Article

\title{
Stories of Supervision
}

\author{
Trish Spedding
}

Faculty Education \& Society, University of Sunderland, St. Peter's Campus, St Peter's Way, Sunderland SR60DD, UK; trish.spedding@sunderland.ac.uk

Received: 3 February 2020; Accepted: 27 March 2020; Published: 31 March 2020

check for updates

\begin{abstract}
This article centres upon experiences of supervising practitioner-researchers engaged in the first year of a Customised Master of Philosophy (MPhil) programme of study. This pathway resides within a larger collaboration between the University of Sunderland's Centre for Excellence in Teacher Training (SUNCETT) and the Education and Training Foundation (ETF) delivering a National Practitioner Research Programme (PRP) in England. It takes as its starting point how non-traditional research students from the further adult and vocational education (FAVE) sector experience entry into the programme and their subsequent development of scholarship and research skills as they pursue their studies at research degree level in higher education (HE). Using six guiding principles underpinning the PRP as a framework for analysis, illustrative stories of the experiences of supervisors and research students provide insights into ways in which supervision is enacted. Some key characteristics of supervision practice are described. These often bring to light differences between supervision on the Customised MPhil with that of conventional MPhil programmes. The most striking finding supports how the development of collaborative and cooperative practice helps to shift the customary dynamic of research degree study away from isolation towards a shared experience as members of an inclusive and active research community.
\end{abstract}

Keywords: supervision; MPhil study; higher education; further adult and vocational education; SUNCETT-ETF Practitioner Research Programme; practitioner-researchers; research students; postgraduate widening participation

\section{Introduction}

This article presents an account of a model of supervision practice, stemming from the experience of supervising practitioner-researchers from the further adult and vocational education (FAVE) sector studying on a Customised Master of Philosophy (MPhil) programme. The account offers a number of insights into the roles, relationships and processes encountered as supervisors of non-traditional, higher degree students. In the context of this study, non-traditional students are FAVE practitioners awarded a place on a Customised MPhil programme. Generally, only a small minority of FAVE practitioners successfully study for an MPhil/PhD with traditional entry to higher degree research, usually the preserve of those already working in higher education (HE). In order to unlock opportunities for FAVE practitioners to participate in higher degree study, the Education and Training Foundation (ETF) in partnership with the University of Sunderland have developed a Practitioner Research Programme (PRP), which is open for application to all practitioners working in FAVE organisations funded by the Education \& Skills Funding Agency (ESFA) in England.

The FAVE sector in the UK is characterised by learners studying for academic, vocational and leisure qualifications, work-based learning, apprenticeship and traineeship programmes and the new 2020 "Technical Level" qualifications. This diverse sector also includes "returners" to learning across the age range and 14-19-year-old learners who have missed out on qualifications in the school sector. FAVE encompasses large multi-campus further education colleges (FECs), independent training 
providers (ITPs), adult and community learning (ACL), work-based learning across industries and offender learning provision. Some provision in FAVE is geared towards entry qualifications to study in the HE sector, with a number of FECs entering into partnerships with HE to provide a limited range of undergraduate and postgraduate qualifications. Different funding systems operate across HE and FAVE, with FAVE having less generous funding arrangements per student than HE and access to professional development for staff reduced. Research has traditionally been a low funding priority for both staff and students in the FAVE sector, standing in stark contrast to the priority given to research in $\mathrm{HE}$ and the emphasis placed on staff to gain higher degrees. Decreased funding and lack of opportunity to access higher research degrees in house limit participation for FAVE practitioners to study at this level. The four home nations of the UK, England, Scotland, Wales and Northern Ireland, share in their general attributes but have separate funding and policy arrangements. The focus of the study in this article refers only to the FAVE sector in England.

The Customised MPhil is a pathway within the larger SUNCETT-ETF Practitioner Research Programme (PRP), a national programme of practitioner-research funded by the ETF, the national representative body for the FAVE sector in England and designed and delivered by the University of Sunderland's Centre for Excellence in Teacher Training (SUNCETT). The PRP aims to develop understandings of practice-focused educational research including its role in improving educational practice and its potential to contribute to theory. The overarching purpose of the ETF-SUNCETT PRP is to create epistemic conditions in which FAVE practitioners, education leaders, policy professionals and university researchers can talk openly about problematic aspects of educational practice in the sector from a practitioner's perspective and in the context of direct experience. A number of articles in this Special Issue focus on experience of the PRP, for further detailed discussion elsewhere, see, Gregson and Spedding [1]; Gregson et al. [2]; Gregson and Spedding [3].

Within the ETF-SUNCETT PRP, two distinct qualification programmes operate, the Master of Arts (MA) Short Course and the Customised MPhil. The MA Short Course is a one-year, 30-credit programme at the master's degree level, providing an introduction to research. The MA Short Course supports the development of a small-scale, practice-focused project aimed specifically at sector practitioners with little experience in conducting research. Support includes payment of course fee, three two-day residential research development workshops led by SUNCETT, a research mentor and dissemination of research findings in a poster presentation at the annual national practitioner research conference sponsored by ETF.

The Customised MPhil is a two-year higher research degree aimed at supporting FAVE practitioners motivated to develop research capacity to successfully access and gain entry to MPhil study. The customised nature of the programme resides in the partnership between the ETF and SUNCETT, making possible access to higher degrees for FAVE practitioners that would otherwise be lost. Customisation is through a programme of support which includes payment of MPhil fees for two years (with a contribution to fees by participants in Year 2), six three-day residential research development workshops led by SUNCETT, dedicated research supervisors, monthly telephone supervision tutorials and dissemination of findings in research papers presented at the annual national practitioner research conference sponsored by ETF. As discussed earlier, FAVE practitioners have limited opportunities to participate in higher degree study, and this Customised MPhil programme provides a much-needed space for the development of research dedicated to their needs. The design of the programme ensures that practitioners have opportunities to develop and maintain a research community as well as to work alone on their individual projects. The distinctive nature of the customised programme and the differences separating it out from standard MPhil programmes are considered in detail throughout this article. Sections 2.3 and 2.4 centre on application to MPhil study with Sections 4 and 5 presenting a critical examination of the major contrasts between the two approaches to MPhil study.

The relationship between the six guiding principles of the PRP and the development of a model of higher education supervision form the key focus for discussion in this article. Following Connelly and Clandinin [4], a chronology centred on the first year of Customised MPhil study provides the 
"scene and plot", which frame the study. Examples are drawn from the direct experiences of students and supervisors.

The account presented here is best considered a story rather than a blueprint or recipe for supervision. A number of texts already provide advice to supervisors, see for example, Taylor et al. [5] and Peelo [6]. The story set out here illustrates how a number of Customised MPhil students made progress in the development of their research, scholarship, knowledge and skills over the period of a year.

\section{Materials and Methods}

\subsection{The Inside Story}

This section sets the scene for the particular context in which the Customised MPhil operates and how beginning practitioner-researchers make the transition from non-traditional applicants to a programme of research, to beginning researchers and ultimately to higher-degree-level research students in HE. The ways in which a corresponding model of supervision has developed and grown are discussed through alignment to the guiding principles of the PRP itself.

\subsection{Encounters of the First Stage: Application One}

Each year, FAVE practitioners from across England are encouraged by ETF and SUNCETT to apply for a place $n$ the PRP. The programme is advertised on the ETF website and communicated to sector leaders in further education colleges and other sites of adult and vocational learning. It is noticeable that many applications are referred to the PRP via "word of mouth", demonstrating the powerful effect that involvement in the programme (or previous versions of it) has had upon practitioners and education leaders in the sector.

Application to the PRP requires practitioners to submit a written research proposal focusing on an aspect of educational practice identified by them as being in need of improvement and to specify their chosen pathway of study, either the one-year MA Short Course or the two-year Customised MPhil. Written applications are considered by the ETF and SUNCETT teams and are carefully scored and moderated before shortlisting onward to the next stage of selection. All shortlisted applicants are invited for a telephone interview to enable further exploration of their proposal with members of the team.

It is at the telephone interview that the SUNCETT-ETF team really begins the process of supporting the practitioner-researcher. It is not unusual for applicants to "tick both boxes" on the application form or to identify the "MPhil only" option in relation to choosing a pathway for study. This decision may reside in an ambiguity in the form or perhaps an instinct to keep options open or even to select the Customised MPhil because it is a two-year programme. Either way, it is an important part of the interview for SUNCETT and ETF to ensure the right applicant is allocated a place on the most appropriate pathway. During interviews, it often emerges that applicants are not fully aware of the demands of MPhil study and of the critical differences between an MPhil and a taught MA/MSc or undergraduate study. Whilst many FAVE practitioners have first degrees, with increasing numbers having master's qualifications, it is still the case that, for many, industry qualifications are the norm, see Orr and Simmons [7]. For many applicants, their qualifications were undertaken many years ago, and for the majority, this is their first serious study in a long time. Tackling the issue of suitability to the programme is a focus during the opening stages of the interview, and the team often find themselves being sensitive to the aspirations of the applicant. For the above reasons, the decision for many applicants is to offer them a place on the one-year MA Short Course, which then acts as an introduction to their return to study and research. Overwhelmingly, practitioner-researchers counselled to this pathway tell us that they would have struggled with the Customised MPhil straight off. They describe how the MA provides them with an important grounding in research methods and the means to build their scholarly confidence. In effect, this pathway often provides a stepping stone for many to progress 
to the Customised MPhil. Around 57\% of Customised MPhil cohorts since 2017 consist of people who have successfully achieved their MA Short Course with us. That said, prior study on the MA Short Course is not an automatic determinant of progression to the Customised MPhil. There have been a number of examples where applications from previous MA Short Course students did not reach the standard expected for the Customised MPhil. Although only in relation to a minority of applicants, it illustrates to the team that possible assumptions about the quality of applications from students previously studying with us cannot be taken for granted.

It is noticeable that, for some applicants, the quality of their initial ETF application falls short of what might be seen as traditionally acceptable in a programme of higher degree study. This mirrors the reality that, for many FAVE applicants, it is likely that they are unfamiliar with the conventions of writing research proposals.

The SUNCETT team has considerable experience in supervising students on Masters, MPhil and $\mathrm{PhD}$ study and has developed an eye for identifying the "worth" or, perhaps, more accurately, the "potential" of a research proposal. Recognising the need to suspend (in the early stages at least) the necessity for a perfectly completed initial application form in favour of good ideas is therefore crucial. Ideas are brought to life through the supportive processes of the PRP and the design features of the Customised MPhil programme. The human connection to the proposal is a case in point. It is striking just how passionate FAVE practitioners are about their proposed research. Even more striking are the ways in which they talk about the positive impact such research might have upon the lives of their own learners. The need for the careful and balanced judgement of a research proposal requires at least the opportunity to delve a little deeper into such cases. This might be especially so if the idea is good but the rationale and focus for research is underdeveloped. Another obstacle to be negotiated in proposals is the tendency to highlight the findings of the research before the work has been done. This is not an uncommon phenomenon, which underscores the need to further explore the realities of what conducting educational research actually entails. For many in HE, the gold standard for determining quality of research proposals resides in reference to the work of others in the field. This is a fair argument, at least in theory, but to automatically discount a proposal lacking in references from candidates to this programme would be overly discriminative and somewhat short-sighted at the initial stage of the programme. The need to tease out ideas and explore possibilities, including the realities of what candidates actually know but did not recognise as being a necessary component of their proposal, is of critical importance during the telephone interview.

Naturally, not every candidate will progress to a place in the programme. All candidates who are not offered a place at the initial application stage or following the interview are offered spoken or written feedback regarding how to strengthen future research proposals and are encouraged to continue to develop their research ideas.

\subsection{Encounters of the Second Stage: Application Two}

Application in the first instance is for a general place in the SUNCETT-ETF programme. Following a successful interview, those candidates offered a place on the Customised MPhil pathway are supported in preparing a standard MPhil research application form, which is required for direct application to the University of Sunderland as a graduate research student. Applicants must then satisfy University of Sunderland regulations governing research student entry, including the request for a place, identification of a supervisor, the presentation and defence of a robust research proposal and a panel interview conducted by members of the wider academic research community from across the University.

As discussed earlier, the interview process gives candidates an opportunity to explore the rationale for their research and to begin to make connections through discussion with the team as to how to strengthen their proposal further. Through careful probing, interviewers are often able to tease out the very heart of the proposal and make suggestions as to how and why it would have been useful to document this in the initial written proposal. Throughout their working lives, FAVE practitioners 
are routinely expected to produce a number of reports, in relation to quality assuring programmes and in preparation for Ofsted inspection, see Coffield [8] and Ball [9]. However, such reports are often target-driven, led by data on admissions, retention, achievement and progression; largely descriptive; and sometimes evaluative in nature, with little, if any, critique or reference to research. It is unusual for FAVE practitioners to have the experiences of their HE counterparts in putting research proposals and bids together as part of their professional role. Such lack of opportunity puts FAVE practitioners at a disadvantage when applying for programmes of research study. In essence, the FAVE practitioner can be seen as a non-traditional student in this context, which in turn requires a different approach to admissions in the first instance, see McGivney [10]. This does not in any way suggest a "dumbing down" of the requirements of MPhil study but, rather, recognises that sometimes things need to be different in order to support the inclusion of groups traditionally excluded from higher degree study, see Marshall et al. [11]. Growing evidence from the PRP shows that once in the programme, the scholarly outputs of participants are equal to, and, at times, exceed, that of the traditional entrant in terms of progression through annual monitoring reviews, evaluative reports, published research papers and chapters in books, presentations at conferences, viva voce examinations, etc. Furthermore, a number of practitioner-researchers who began the programme in 2017 have transferred to the PhD track from the Customised MPhil. At the time of writing, four of the six Customised MPhil Year 2 starters are on schedule to submit their PhD theses in the Spring of 2020. A further nine who started Year 1 in 2017 successfully transferred to the PhD track in 2019 and are scheduled to submit their PhD theses in 2021. This represents 59\% of the total cohort at the submission stage. The number of students capable of and who wish to progress to the PhD level is a testament to the success of the customised programme of support at the MPhil level and the capacities and commitment of individual practitioner-researchers to continue their research at this higher level of study.

\subsection{Nearly There...}

It is made very clear to candidates in the interview and in the subsequent offer letter that their place in the PRP is dependent on successfully meeting the requirements of entry to the University of Sunderland's standard MPhil programme. If a candidate falls short of these requirements, then the offer of a place in the PRP is withdrawn. The offer letter explains University application stages, which research students need to complete before and during the first residential research workshop for the University of Sunderland MPhil programme. Candidates are prompted to be mindful of discussions and advice in the interview and to begin drafting their formal research application to the University in advance of the first residential research development workshop. It is absolutely essential that students on the Customised MPhil programme follow and are subject to the same regulations as any other MPhil student at the University of Sunderland.

\subsection{SUNCETT-ETF Residential Research Development Workshops}

Research development workshops are a vital part of the Customised MPhil, a pathway residing within the wider PRP model of educational evaluation and improvement. As FAVE practitioners are recruited from across England, the workshops are by necessity residential and the programme of support from ETF covers the costs of residential events. Attendance at residential workshops are non-negotiable, and a signed agreement to attend together with approval from the practitioner-researcher's line-manager is required at the application stage and confirmed at the interview. Workshops are deliberately planned to take place during the week rather than on the weekends, valuing the needs of practitioners to have both time and space conducive to developing thinking and to engage with literature and research. Intensive research development workshops provide the space to investigate how various stakeholders experience and respond to challenges in conducting, completing and reporting their practice-focused research, including sharing the findings of their research with colleagues, wider stakeholders, policy professionals and other researchers in the field. 
Over a ten-month period, PRP participants attend three three-day residential research development workshops in each year of the Customised Master of Philosophy programme. In addition, participants have the support of regular telephone and face-to-face supervision tutorials over the year. Research development workshops use a variety of stories of research and practice as well as creative media to help practitioners from the sector research to improve an aspect of their practice. Methods used include stories of educational research, practice and knowledge development; narrative enquiry; multimedia ICT-based games and conventional board games; music; film and art. These resources enable and encourage practitioners to engage deeply with key ideas and concepts in educational research. Engaging with published educational research texts helps practitioners to deconstruct the research designs of others to see what good research in a range of educational situations looks like. Workshops include critical considerations of rigour, originality and significance in educational research. They also involve in-depth discussion of what it means to be critical; how to read between the lines when reading published educational research texts; and how to develop individual and collective capacities for research and scholarship. The process of practitioners critically evaluating and making sense of epistemological, methodological and educational issues for themselves in the contexts of their own practices resides at the core of the PRP.

At the end of each residential research development workshop, participants are invited to write a "postcard" detailing the most memorable points for them from that event. Participants complete the postcard on the final day of the workshop and are reminded to think about experiences across all three days. The postcard is represented on A4 paper, and participants complete their card by hand during a quiet fifteen-minute recess towards the end of the final day. Postcards are left by participants in a box in the room where the workshop takes place and are collected by SUNCETT supervisors after the close of the workshop. In unusual circumstances, if a participant has to leave before this activity is completed, an electronic version can be emailed after the event. Postcard responses are anonymous, free-ranging and succinct-as the limited space on a postcard dictates! Nevertheless, valuable insights are gained regarding experiences of MPhil study. Extracts from "memorable moments" on PRP postcards provide examples of stories of experience, which illustrate and illuminate the customised model of MPhil supervision and are presented and analysed in the following section.

\section{Results}

\section{Guiding Principles of the PRP}

Six guiding principles have emerged as important for conducting research on the practitioner research programme, see Gregson and Spedding [1,3]. In the context of this article, the principles serve to provide lenses for examining supervision practice. Taking each principle in turn allows for exploration of possible relationships to the ongoing model of supervision. This separation, whilst helpful for analysis, belies the nature of their dynamic and overlapping interaction in practice.

\section{Principle 1. Direct, practical, cooperative and mutual engagement in practice-focused research is a central principle in the SUNCETT-ETF PRP.}

This suggests that the starting point for educational research should be an issue or concern in educational practice identified by the practitioner in the context of their own professional experience. Dewey [12] and Hunt [13] support the view that practitioners interested in improving educational practice should begin with themselves and value their direct experiences of practice. For Hunt, the starting point in the change process is personal and practicalknowledge, rather than theoretical, knowledge. He shows us that by Beginning with Ourselves and taking experience seriously, we can test and challenge theory in the arena of practice and thereby contribute to the improvement of practice and theory development.

This of course provides impetus for the further development of the research proposal on the Customised MPhil pathway. As discussed earlier, the role of supervision begins during the initial 
application stage with supervisors recognising the need to "dig a little deeper". This ensures that the educational issue identified as being in need of improvement (the focus of the research) is both relevant and directly related to the practitioner and not something that someone else (for example, their college principal, head of department or line manager requires them to pursue). Ownership of the issue/problem and the unique situation that FAVE practitioners as insider-researchers find themselves in brings both advantages and pitfalls in the research process. Careful, cooperative supervision is required to ensure that Customised MPhil students remain focused, ethically secure and confident about issues relevant to insider and practice-focused-research. The following extracts from evaluative postcards illustrate these points:

Residentials give real focus to my research.

Really enjoyed working on my ethical statement and draft statement. Really good to have dedicated time to complete these. It was also very beneficial to see other researchers on the programme to see their statements and summaries.

Being given the space and guidance to complete our ethical statement and summary.... I found it useful to read others and peer assess .... Finally, I've taken away the idea of writing for a point rather than waffling!

Principle 2. Each PRP participant should have the support of a research active mentor from a University who has previously worked as a teacher in the FAVE sector and who has maintained direct contact with the sector.

It is not difficult to see the direct relationship between this principle and that of the traditional research supervisor. The description "research active mentor" is an inclusive term spanning different pathways on the PRP. In essence, the term is inter-changeable with "research supervisor" in the context of the Customised MPhil. The important point to note here is the suggestion of some mutuality in the relationship, a recognition of the experiential value of both the mentee (practitioner-researcher/research student) and the mentor (academic supervisor). Having knowledge and understanding of the context and culture in which the practitioner-researcher works is a key determinant in building successful relationships. The credibility of the supervisor hangs not only on theoretical and academic knowledge but also on their practical and experiential knowledge of working in the FAVE sector. Exemplified through the range of FAVE-centred programmes of study supervisors teach and/or manage and of critical importance the publication of their own research and the monitoring of the volume, nature, depth, relevance and up-to-dateness of PRP research projects in FAVE contexts. Members of the SUNCETT team are in a unique position to support sector practitioner-researchers, not only through ongoing published research, but also via their other professional connections including membership on national expert panels, representation at national meetings of university councils, invitations to speak at sector-led research events and organising and leading FAVE professional development events on a national and international scale, as well as more recent invitations to mentor national ETF technical fellows of the Royal Commission for the Exhibition of 1851. Our contact with the sector is both strategic and practical, ensuring that up-to-date knowledge and skills remain at the forefront of practice-focused research activity.

Examples of this impact on participants include the following comments:

New ideas and sources of research to access. Gaining a new perspective on what the purpose of my research is and how I can implement it ... Sharing ideas with other professionals... Knowledge and expertise of the delivery team.

The excellent delivery from everyone made me feel invigorated and excited for my research. Research is an area I have been scared of before but you have all made me feel like I can do this. Thank you so much!

Being guided by expert researchers ... Learning from peers— great ideas for projects—-their enthusiasm and commitment .... Excellent investment of time to allow me to develop skills and thinking and the project. 
Meeting fellow practitioners ... . The team delivery (you Four)! ... Seeing the progress of my peers' projects ... . Having the opportunity to pursue an interest ... . Making a small difference to the education sector....

Principle 3. Attending a number of residential research development workshops where practitionerresearchers work alongside a research-active mentor of the SUNCETT team helps practitioners to begin to engage in the research process by enabling them to talk openly about the "problem in practice" and to think about it more carefully in order to try to develop a deeper understanding of the nature of the problem and the extent to which the work of other researchers might contribute to helping to address the problem.

Supervisors work together to create spaces where experience is accepted and real and where truth can emerge. The dominant culture of compliance and performativity in the FAVE sector, see Coffield [8] and Ball [9], can make it difficult for practitioners to talk about what is really happening in practice and how often they are expected to act as if experience is not real and as if remote, decontextualized standards and fabricated measures of performance are real. The design of research development workshops opens up a space where this can happen, sometimes as a community with collaborative and peer activities and sometimes with individual one-to-one supervisory tutorials. Essentially workshops aim to support the development of trust, dialogue, confidence, scholarship, mutual engagement, belonging and agency in epistemic conditions where problem finding, problem-solving and critique can flourish in practice. Evidence from data derived from evaluative postcards from the PRP strongly support this, as the following examples illustrate:

Day 1 really helpful to crack ontology/epistemology lots of active learning. ... 3 groups task really helpful ... Question Time was fun .... .

The peer support and sharing of research progress ... The excellent support and supervision from SUNCETT.

Talking to other practitioners allow you to gauge your progress and an opportunity to discuss research with tutors on the same journey... It always gives me a shot in the arm and helps keep the impetus going.

Opportunities to develop scholarship through spoken and written language are cited by many as important:

Really enjoyed the opportunity to 'think' and taking part in a real scholarly discussion and now I really have something to say....

Comparing abstracts - really hate comparisons but found it very helpful in the end (there's no gain without the graft!) great feedback from tutor... Reworking poster/abstract has deepened understanding of the subject... Poster presentation - so helpful to see and analyse different approaches.

Creating and presenting my poster so that I now have a way of presenting my research so far at the (National) Conference. Receiving feedback on my draft chapter to support refining my ideas and writing.

Starting to get used to the pace and developing my reading and range at every residential ... Proud of myself and how I can see my progression in my writing ... Produced a strong abstract without having a meltdown ....

Principle 4. The mentor (supervisor) and the practitioner-researcher embark on a process of cooperation and mutual engagement in identifying an intervention that may potentially address the problem in practice.

This principle, although central to the one-to-one "mentor/supervisor-practitioner-researcher/research student relationship", also calls upon the research community in that the Customised MPhil model 
develops by drawing upon the experiences of the whole team and all practitioner-researchers in the cohort. A significant difference in the design of the Customised MPhil comes into play here. For most people, embarking on an MPhil it is a solitary experience confined to the relationship between student and supervisor. Standard university programmes may have on- and offline opportunities for students to come together at, for example, a seminar on research methods or an invite to a research network. However, it remains the case that for most of the time, students on a standard MPhil programme work alone on their project with varying degrees of feedback from a designated supervisor. The ways in which isolation is reduced on the Customised MPhil are significant. A sense of being part of a community of research, Wenger [14], rather than a solitary experience comes through loud and clear in these extracts from student postcards:

Equally important is the feeling of belonging to a community of like-minded people tackling similar issues within their educational practice.

The relaxed range of ways we have shared our research stages continue to hone my thinking. Wonderful to learn from others' experiences and styles of structures to aid learning.

It was the time allowed to reflect on the direction my research is going. Also to run ideas with other researchers.

I really enjoyed meeting the other researchers and building links and sharing ideas. I am a lot more confident in my ability and in the project after this residential.

Thoroughly enjoyed the residential. It has been inspiring to have the opportunity to meet with other professionals to explore our sector. Really excited to what this year brings!

This sense of community and "shared experience" is a recurring theme in data from participants, extending the idea of community between and beyond residential events:

Meeting others in the same boat_creating a community through WhatsApp/email will be very useful.

... Discussing and clarifying ideas with mentor was very useful.

Having tutorial time to further develop and focus our research. Having the opportunity to meet and discuss with others undertaking research.

Seeing how far fellow members of the community have progressed... Sharing ways of expressing work done to date.

At this stage in the PRP, practitioner-researchers then implement a research intervention and examine the consequences of the intervention in practice in collaboration with their mentor. It is important to note here that this is not a one-way process in which practitioners simply apply the ideas and theories of others to their own practice, or where the mentor simply tells them what to do. On the contrary, it is a process through which practitioners and their mentors question and challenge theory, test theory and research in the arena of practice and connect their findings with published research in light of and with reference to their experiences of practice. In this way, participants in the PRP use practical experience to contribute to the development of theory, research and practice. They develop the courage, care and qualities of mind to critically examine and challenge ideas from research conducted by others in the arena of their practice. The following example refers to a guest lecture/seminar by Professor Terry Hyland where participants were able to clarify ideas and ask questions beyond the formal seminar as part of the residential workshop:

Brilliantly tailored ideas and resources to aid reflection and move the research forward... . Terry was inspiring! Fitted perfectly with my area of interest.

Principle 5. Each residential workshop is designed to reflect relevant stages in the research process.

At each workshop, mentors/supervisors provide stage-relevant research training for PRP participants. It is important to note that this involves SUNCETT and other invited research mentors 
sharing their own experiences of research with PRP participants at each stage in the research process, including mistakes made and lessons learned. From our own practice, for example, we share the experience (good and bad) of doing a PhD, conducting a large longitudinal study, challenges of working in a mixed qualitative/quantitative research team and completing a commissioned systematic review.

The design of residential research development workshops provides time and space where Customised MPhil participants can talk openly with their mentor and other participants about what is really happening in practice. This element of design was without a doubt the most significant to participants, with the majority making reference to this in conversation with us or as shown here in the following extracts from postcards:

Really refreshing to have the time and space away from college to actually think about the pedagogy that underpins what we do every day.

The chance to work on my research and writing in an uninterrupted environment (next to the beach no less) has been a huge benefit to me as a student researcher.

Having time and support to further develop projects.

Being given the time and opportunity to talk to other practitioners and finalise otherwise very 'fluffy' ideas ... . I definitely feel like I have more of a direction in my studies.

Really enjoyed the focussing sessions and then the time and space to work on my abstract and poster.

This way of working gives PRP practitioner-researchers the freedom to examine the consequences of their actions and to make practical judgements together. Take for example, the following:

Seeing the significant progress everyone has made with their project ... The confidence I have gained by knowing I have a viable (and interesting) project!!!

I have found it really beneficial discussing ideas and the support as always has been great. I feel I have what I need to complete the work been given.

Chance to discuss project with peers and share ideas and feedback.

All of the detailed feedback on progress to date. Really enjoyed sharing ideas with peers.

Lots of great presentations, very interesting to see other projects, how they're getting on and to share ideas.

Workshops also provide space and time to think, time to read and time to write about what is happening in practice with reference to the work of others who have thought, read and written about the same issues in educational (and other forms of) practice. PRP participants made the following comments:

The 'Question Time' task linked to epistemology really brought a wide range of research positions to life .... An amazing residential that was supportive, developmental and of value to my research.

Learning about methodology was difficult and complex but was a fantastic place to work through this ... videos .... Examples of real life research.

I particularly enjoyed the self-study period we received this allowed me to work alone on my thesis and not be distracted by outside influence.

The readings at the residential were/have been really useful .... .

Chance to think through methodological theories to inform chapter 3 ... Sharing ideas and experiences with others.

The work on Methodology was helpful and useful although challenging as a totally new subject to me.

Principle 6. Each practitioner-researcher is expected to prepare, present and justify the findings of their research. 
A significant aspect of the Customised MPhil supervision is the way in which supervisors track progress, support the development of scholarship and encourage the wider dissemination of research in progress. As with all MPhil programmes, there is a minimum requirement at the end of year, which culminates in an annual monitoring review (AMR). This includes production of draft chapters, an evaluative commentary documenting progress, next steps and reference to any conferences/presentations/publications that have been generated. In addition, on the first year of the Customised MPhil pathway, a research poster, abstract and workshop presentation are required at the Foundation's National Annual Research Conference in London. Conference outputs are shared with the representatives from ETF and made accessible to practitioners in the sector via the ETF website and through regular updates on practitioner-research in the Society for Education and Training's (SET) professional research journal In-Tuition. In addition to mandatory assessed outcomes, a burgeoning collection of published research outputs from practitioner-researchers is now in the public domain. These include, research papers in peer-reviewed journals; chapters in books; articles in professional journals; presentations at regional, national and international conferences; workplace CPD events; and contributions to research networks, blogs and think pieces. PRP participants are contributing to this Special Issue, others have authored contributory chapters to a recent book on practitioner research [1], and many present work at education conferences regionally, nationally and internationally. Some specific details of Customised MPhil students' research outputs and their impact can be found in the opening article of this Special Issue.

\section{Discussion}

\subsection{The Whole is Greater than the Sum of Its Parts}

By presenting examples of supervising non-traditional students and by exploring how this relationship connects to the "six guiding principles of the PRP", a number of interesting findings emerge. The "principles" provide not only a framework for exploring supervision but also help us to see that this approach to supervision resides at the very core of the Customised MPhil programme. This is perhaps not so unusual when you consider that, in any research degree programme, the supervisor is in effect the lynchpin. What is different and significant here is that the ETF-SUNCETT Customised MPhil programme does not rely entirely on one pin! Traditionally doing a research degree involves two key people-the student researcher and the supervisor. Other people are involved at occasional points in the process, such as participants, academic assessors, external examiners and staff regulating the degree, but mainly the standard MPhil experience is a solitary one for the student with only the supervisor for support; sometimes, a second supervisor may be involved. The very nature of doing a higher degree by research means it is unusual to have collaborative and cooperative taught elements. Although, as discussed earlier, some universities provide access to shared workshops such as training in research methods or data analysis; often these are online and atomised rather than sequential, coherent and face-to-face. Opportunities to be part of an online community might exist through research networks, and this is something we encourage our own students to be part of where appropriate. However, immersion in an ongoing, consistently and coherently connected, highly active research community is unlikely. The creation and maintenance of a dynamic and supportive research community is key to the very different approach that the Customised MPhil has taken and, by extension, the way in which supervision practice supports this.

All practitioner-researchers on the Customised MPhil programme talk about the significance of being part of a collaborative and cooperative community. A key finding from this study is that PRP practitioner-researchers value the shared experience that comes about through seeing themselves and their dedicated supervisor as legitimate members of a bigger research community and that the one-to-one relationship they have with the supervisor is enhanced by the support of the whole PRP community and a critical friend from their peer group. 
Because the supervisor is a member of that same community, all PRP supervisors function to support other students both as a whole group as well as on the designated one-to-one basis. The Customised MPhil supervisor-student relationship feels less isolated.

All supervisors involved in the PRP spend time in a variety of roles, including whole-class teaching, group tutorials and talking to everyone in the informal spaces purposefully created to open up and support conversations about research, the nature of knowledge and knowing and the work of other educational researchers.

These spaces include time at the beginning and end of formal taught sessions, coffee breaks, mealtimes and other periods in the evening or "drop in surgeries" during independent study time, when students can talk to anyone on the supervision team rather than only their designated supervisor/mentor. Students often refer to how this collective supervision activity, both from their designated supervisor and from other members of the SUNCETT team, is an important aspect of the PRP. Examples illustrate this through references in evaluative "postcards" to SUNCETT, the team, "all of you", etc. A key finding here is the need to see supervision as more than simply a one-to-one relationship.

Examples in Section 3 illuminate how collaborative approaches developed in the Customised MPhil shift encounters for students away from the solitary to a shared experience. The inclusion of group activities designed to develop conceptual understanding peer review of abstracts and summaries, sharing extracts of draft chapters to progress academic writing and presentations of work designed to develop students' spoken language and the research 'voices' required for different audiences are important features of this Customised MPhil programme. Incrementally building confidence and a sense of agency are critical, as is support from the whole cohort. These are key to the PRP process. As illustrated previously, students clearly endorse this approach. They value ways to learn from each other, share ideas/resources and keep in touch. It is relatively easy to imagine how these relationships extend to talking to each other about experiences of supervision either with the same or with a different supervisor! Such conversations help develop a certain tenacity in students, pointing to skills they can transfer with greater confidence when speaking in the more traditional set up of the one-to-one tutorial.

Supervision tutorials are a significant component of the programme and provide space to develop trusting, open and working relationships with individual students. They enable detailed, nuanced feedback on drafts of chapters for theses and monitor progress. Face-to-face tutorials with individual students take place at residential research development workshops. Crucially, these are supplemented by monthly one-to-one telephone tutorials in between residential workshops. Supervisors usually see their "own" students as a group before leaving residentials, ensuring that "next steps" are understood and arrangements finalised regarding the dates and times of individual telephone tutorials.

\subsection{You've Got It! Critical Moments}

Critical moments are those times when PRP supervisors can almost see when students "get it". Rather than the Eureka moments of research, they appear most often after a period of time, when the activity involved in one-to-one supervision takes a shift in direction. For example, during the early stages of the PRP, supervisors spend more time helping students grasp critical concepts related to the study, make decisions about key literature and crucially develop their written and spoken voice. Students can require a fair amount of support at this point in terms of the development of their written English and use of scholarly language. These are often exemplified through a high percentage of tracked changes and comments in the early stages of drafts of the development of PRP chapters of theses. Supervisor and students work together at this time, co-crafting language appropriate to the study. When supervisors find themselves' making fewer and fewer comments, they know that the student has got it! This can appear in the way students talk about progress, reflecting on their work during residential research development workshops, or, more significantly, when declaring astonishment at how far they have come over their first year. It can be challenging for Customised MPhil students to reach the standard required, but careful, targeted feedback can make huge differences to the progress 
students make. Interestingly, ETF-SUNCETT Customised MPhil practitioner-researchers seem to struggle less with carrying out the research, than they do with writing it up.

Many students on the Customised MPhil pathway of the PRP are qualified teachers and, if not in a current teaching role, still have close managerial contact with teachers and will be used to giving feedback but not always so used to receiving it! Coffield [15] uses the metaphor of a tandem to describe the teaching and learning relationship. Its relevance can be seen during one-to-one supervision when the bike requires pedalling from both parties and the times when the supervisor eases the foot off the pedal!

Another finding relevant to good supervision practices are changes in the ways in which students talk about their work. As described earlier, the Customised MPhil relies as much on cooperative and collaborative activities as it does on individual work (although ultimately it is the individual student who carries out and writes up the research thesis!). From the very start, talking about research is encouraged. Unsurprisingly, this is more difficult than it seems. To assume that FAVE practitioners would find it easy to talk about research would be a mistake. Like any other student, the practitioner-researcher in the early stages of the programme can be at quite a loss in finding the right words to talk about their research. Through careful programme design, incremental progress takes place. This is seen most clearly through the development of a research "voice", whereby students talk convincingly about their research together with their ability to moderate this to different audiences. Again, the power of a collaborative, cooperative approach to supervision plays out. Peers and the wider supervisory team are more likely to be able to comment on clear speaking, facilitated by a distance from the research that the designated supervisor may have become too close to or lost. This provides positive advantages in a community of research, where individual students feel confident about receiving feedback from the wider supervision team. It is unusual for students in a traditional MPhil programme to have such naturalistic access to a group of academics in the field beyond their designated supervisor.

\section{Conclusions}

This article set out to discuss the model of supervision supporting SUNCETT-ETF practitioner-researchers/research students on a Customised MPhil programme. The relationship between the six guiding principles of the PRP provide a framework to explore how this model of supervision develops. Through personal, authentic examples taken from student evaluative postcards describing experiences of residential research development workshops, a story illustrating the development of a research culture and a community and model of research supervision emerges.

In addition, feedback collected through these accounts of experience offers a valuable means for supervisors to develop their practice and to continue to improve the Customised MPhil programme. Postcards are "read together" for meaning by the supervisory team immediately after collection at the end of the research development workshop. After this initial "airing" of feedback, a more analytical approach is taken in advance of planning for the next workshop. Postcards are analysed to identify recurring themes and key suggestions. By clustering themes in terms of commonalities or significant outliers, the need for any changes in the direction of practice is signalled and acted upon. Responding to feedback in this way ensures that the programme remains focused on the needs of FAVE practitioners and responsive to the ways in which we provide support as designated supervisors in one-to-one contexts with individuals and as part of a wider team during workshops designed to develop scholarship and research skills.

Through the PRP, University of Sunderland Customised MPhil supervisors and their students are learning to evaluate and improve the practice of education, the practice of research, the practice of theorizing and the practice of scholarship together in cooperation and collaboration. 
Funding: This research was funded in part by the Education \& Training Foundation (ETF) grant number 93381 however the research outcomes from the Practitioner Research Programme (PRP) are arrived at independently through systemic HE supported research. The findings of this research study is therefore not in any way influenced by the partial support from ETF funding.

Conflicts of Interest: The author declares no conflict of interest.

\section{References}

1. Gregson, M.; Spedding, T. (Eds.) Practice Focused Research in Further, Adult and Vocational Education: Shifting Horizons of Educational Practice, Theory and Research; Palgrave-McMillan: London, UK, 2020.

2. Gregson, D.; Gregson, M.; Spedding, T. Top-Down and Outside-In: Breaking Boundaries between Research, Theory and Practice in Education. J. Manag. Policy Pr. 2019, 20, 36-52.

3. Gregson, M.; Spedding, T. Learning Together: Evaluating and improving Further Adult and Vocational Education through practice-focused research. In Trends in vocational education and training research. Proceedings of the European Conference on Educational Research (ECER), Vocational Education and Training Network VETNET; Nägele, C., Stalder, B.E., Eds.; Vocational Education and Training Network VETNET, ECER: Berlin, Germany, 2018; pp. 157-164. [CrossRef]

4. Connelly, F.M.; Clandinin, D.J. Stories of Experience and Narrative Inquiry. Educ. Res. 1990, 19, 2-14. [CrossRef]

5. Taylor, S.; Kiley, M.; Humphrey, R. A Handbook for Doctoral Supervisors, 2nd ed.; Routledge: Abingdon, UK, 2018.

6. Peelo, M. Understanding Supervision and the PhD; Continuum: London, UK, 2010.

7. Orr, K.; Simmons, R. Dual identities: The in-service teacher trainee experience in the English further education sector. J. Vocat. Educ. Train. 2010, 62, 75-88. [CrossRef]

8. Coffield, F. Will the Leopard Change It Spots: A New Model of Inspection for Ofsted; UCL Institute of Education Press: London, UK, 2017.

9. Ball, S. The tragedy of state education in England: Reluctance, compromise and muddle-A system in disarray. J. Br. Acad. 2018, 6, 207-238. [CrossRef]

10. McGivney, V. Staying or Leaving the Course: Non-Completion and Retention of Mature Students in Further and Higher Education; NIACE: London, UK, 2003.

11. Kotowska-Lewińska, M. Collette Snowden, Sally Lewis, Mixed Messages: Public Communication about Higher Education and Non-traditional Students in Australia (Rozbieżne komunikaty: Publiczna dyskusja na temat szkolnictwa wyższego a nietypowi studenci w Australii). High. Educ. 2015, 70, 172-173.

12. Bugg, E.G.; Dewey, J. How We Think: A Restatement of the Relation of Reflective Thinking to the Educative Process. Am. J. Psychol. 1934, 46, 528. [CrossRef]

13. Hunt, D.E. Person, Culture, and the Initiation of Change: Comments on Deborah P. Britzman's Review of Beginning with Ourselves. Curric. Inq. 1990, 20, 75. [CrossRef]

14. Wenger, E. Communities of Practice: Learning, Meaning and Identity; Cambridge University Press: Cambridge, UK, 1999.

15. Coffield, F. All You Ever Wanted to Know About Learning and Teaching but Were Too Cool to Ask; LSN: London, UK, 2009.

(C) 2020 by the author. Licensee MDPI, Basel, Switzerland. This article is an open access article distributed under the terms and conditions of the Creative Commons Attribution (CC BY) license (http://creativecommons.org/licenses/by/4.0/). 